\title{
Hafnium Carbide Coatings Deposited by Suspension Vacuum Plasma Spraying for Ultra-High-Temperature Oxidation Barrier on Carbon Composites
}

\author{
Received 5 November, 2020; revised 3 December, 2020; accepted 8 December, 2020
}

\author{
Yeon Woo Yoo ${ }^{a}$, Uk Hee Namª, Yeontae Kim ${ }^{b}$, Hyung Ik Lee ${ }^{b}$, Jong Kyoo Park ${ }^{b}$, and Eungsun Byon ${ }^{a, *}$ \\ a Extreme Environmental Coatings Department, Surface Technology Division, Korea Institute of Materials Science, \\ Changwon 51508, Republic of Korea \\ bThe 4th R\&D Institute, Agency for Defense Development, Daejeon 34186, Republic of Korea
}

\author{
*Corresponding author E-mail: esbyon@kims.re.kr
}

\begin{abstract}
Hafnium carbide (HfC) coatings on carbon composites have been extensively researched owing to their excellent high-temperature properties. However, it is still challenging to fabricate thick coatings. Vacuum plasma spraying is one of the methods of fabricating thick coatings. However, the formation of dense coatings is a problem because conventional sized thermal spray powders possessing ultra-high melting temperatures cannot be satisfactorily melted. In this study, a dense $50-\mu \mathrm{m}$-thick HfC coating was fabricated via suspension vacuum plasma spraying using nanometer-sized powders. The HfC coating was characterized through scanning electron microscopy and X-ray diffraction. The HfC coating contained hafnium oxide owing to the reaction with the oxygen present in the solvent during the spraying process. The ultra-high-temperature oxidation resistance of the $\mathrm{HfC}$ coating was determined by performing a laser oxidation test at $2000^{\circ} \mathrm{C}$. The weight reduction rate of HfC-coated carbon composites was seven times less than that of uncoated carbon composites.
\end{abstract}

Keywords: Hafnium carbide, Vacuum plasma spraying, Suspension plasma spraying, Ultra-high-temperature oxidation

\section{Introduction}

Hafnium carbide (HfC) is used as an ablation-resistant material in hypersonic vehicles because of its high melting temperature of over $3700{ }^{\circ} \mathrm{C}$, chemical stability, and excellent mechanical properties at high temperatures [1-3]. However, it is vulnerable to external impact because of its unique brittle nature that is similar to those of ceramics. Therefore, it is used as a composite material with silicon carbide ( $\mathrm{SiC})$ fibers or carbon fibers to compensate for its brittleness and improve the ablation properties of $\mathrm{SiC}$ or carbon composites [3-6]. It is challenging to use HfC in flight vehicles because its density $(\rho=12.2$ $\left.\mathrm{g} / \mathrm{cm}^{3}\right)$ is extremely high, and this leads to an increase in the weight of flight vehicles. To resolve this issue, considerable effort has been dedicated to fabricating the interiors of flight vehicles using relatively light carbon composites and $\mathrm{SiC}$ composites with a HfC coating on the surface.

HfC coatings can be fabricated using various processes such as chemical vapor deposition (CVD) [7-11], physical vapor deposition $[12,13]$, and plasma spraying [14-18]. CVD is the oldest process for fabricating $\mathrm{HfC}$ coatings, and dense and uniform $\mathrm{HfC}$ coatings can be obtained by reacting hafnium tetrachloride and methane at a high temperature. However, there are limitations on the coating area, and the coating deposition rate is low. This increases the process time while fabricating a thick HfC coating [7-11]. HfC coatings can also be deposited by a reactive sputtering process using a hafnium (Hf) metal target. However, this process is not suitable for fabricating micrometerthick coatings owing to a low deposition rate $[12,13]$. Plasma spray- ing processes have been introduced to overcome the disadvantages of conventional processes, and HfC coatings have been fabricated by utilizing supersonic atmospheric plasma spraying and vacuum plasma spraying methods. The $\mathrm{HfC}$ coatings and $\mathrm{HfC}-\mathrm{SiC}$ composite coatings that are fabricated using supersonic atmospheric plasma spraying have a porous microstructure, and $\mathrm{HfC}$ oxidation occurs during the process [14-16]. However, vacuum plasma spraying provides HfC coatings with a denser microstructure and prevents the oxidation of HfC because the process is carried out in vacuum [17]. The mean free path of the ions that constitute a plasma flame is affected by the number of surrounding particles. The mean free path of ions increases as pressure decreases. This increases the length of the plasma flame. Consequently, the dwell time increases, which results in an excellent melting state compared with that obtained through atmospheric plasma spraying.

The particle size of conventional thermal spray powders is in the range of $30-80 \mu \mathrm{m}$. In the case of materials with a high melting temperature of over $3700{ }^{\circ} \mathrm{C}$, such as tantalum carbide (TaC) and $\mathrm{HfC}$, it is difficult to heat the powders to the melting temperature within a short dwell time. Figure 1(a) shows the scanning electron microscopy (SEM) image of $\mathrm{TaC}$ powders with a conventional particle size for thermal spraying. Figures 1(b) and 1(c) show the surface and crosssectional SEM images, respectively, of molten $\mathrm{TaC}$ powder injected into a plasma flame. The surface of the molten $\mathrm{TaC}$ powder appears smooth and well melted. However, the inside of the powder did not melt, and melting occurred only on the surface. Even though the size of spray powders can be reduced to ensure that they melt com- 

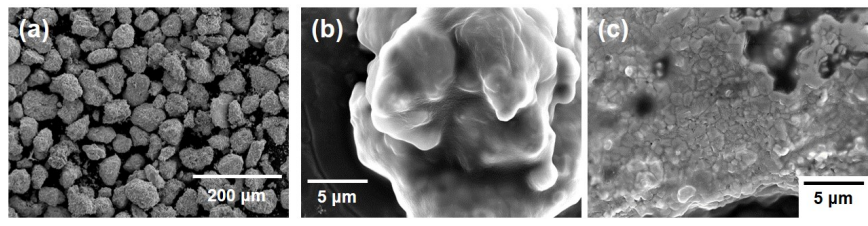

Figure 1. (a) SEM image of TaC powders with conventional sized thermal spraying powders, (b) surface SEM image of molten TaC powder injected into a plasma flame, and (c) cross-sectional SEM image of molten TaC powder injected into a plasma flame.

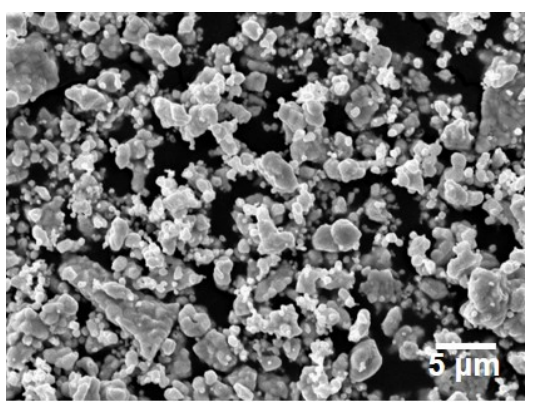

Figure 2. SEM image of as-received $\mathrm{HfC}$ powder.

pletely, it is difficult to inject small powders into a plasma flame. Suspension plasma spraying (SPS) was introduced to conveniently carry and inject submicrometer-sized and nanosized powders into a plasma flame [19-22]. In SPS, submicrometer-sized to nanometer-sized powders dispersed in a liquid solvent are carried and injected into a plasma flame and melted to form a coating.

In this study, HfC powders with a high melting temperature were prepared as a suspension, and thick HfC coatings were fabricated by performing suspension vacuum plasma spraying (SVPS) in a vacuum chamber.

\section{Experimental details}

Figure 2 shows the SEM image of the HfC powder (Japan New Metals Co., Ltd.) used in this study. The mean particle size of the HfC powder was $7.08 \mu \mathrm{m}$, as measured using the laser diffraction method. A high-energy ball mill (8000 D, SPEX SamplePrep) and tungsten carbide balls were used to prepare a HfC suspension. The crushed powders were weighed and mixed with a dispersant and an ethanol solvent to prepare the suspension. $\mathrm{HfC}$ coatings were fabricated using the prepared HfC suspensions in modified vacuum plasma spraying equipment (GTV GmbH). The plasma gas used in SVPS was a mixture of argon and hydrogen $\left(\mathrm{H}_{2}\right)$. The plasma flame power was maintained at $55 \mathrm{~kW}$. SVPS was performed in an inert environment to prevent oxidation during the spraying process. Nitrogen was used to provide an inert atmosphere. The HfC suspension was atomized and injected

Table 1. Suspension vacuum plasma spray parameters of $\mathrm{HfC}$ coatings

\begin{tabular}{l|l}
\hline Spray parameters & Value \\
\hline Primary gas flow & $20 \mathrm{SLM}$ \\
Secondary gas flow & $15 \mathrm{SLM}$ \\
Spraying speed & $60 \mathrm{~mm} / \mathrm{s}$ \\
Stand-off distance & $150 \mathrm{~mm}$ \\
Suspension feed rate & $\sim 15 \mathrm{~g} / \mathrm{min}$ \\
Atomizing pressure & $1 \mathrm{bar}$
\end{tabular}

into the plasma flame through two fluid nozzles. The SVPS parameters are summarized in Table 1. SiC-coated carbon composites using the CVD method were used as substrates. The phase of the HfC coatings was analyzed via X-ray diffraction (XRD, X-pert PRO, PANalytical). To observe the cross-sectional microstructures of the HfC coatings, the specimens were cut and cold mounted, and their surfaces were polished before SEM analysis (IT-300, JEOL). The ultra-high-temperature oxidation resistance of the $\mathrm{HfC}$ coatings at $2000{ }^{\circ} \mathrm{C}$ was determined by performing laser oxidation tests.

\section{Results and discussion}

It is difficult to disperse submicrometer-sized HfC powders to produce a suspension because $\mathrm{HfC}$ is quite dense. Therefore, the HfC powders were crushed to the nanometer scale using high-energy ball milling. Figures 3(a) and 3(b) show the SEM image and size distribution of the crushed HfC powders, respectively. The mean particle size of the HfC powders decreased from $7.082 \mu \mathrm{m}$ to approximately 200 $\mathrm{nm}$ owing to high-energy ball milling. In addition, the sizes of most of the particles in the HfC powders were less than $1 \mu \mathrm{m}$, except for the agglomerated powders.

Figure 4 shows the cross-sectional SEM images of the microstructure of the HfC coating fabricated via SVPS. Figure 4(a) shows that a $\mathrm{HfC}$ coating was formed on the $\mathrm{SiC}$ layer at a working pressure of 100 mbar using a $10 \mathrm{wt} \% \mathrm{HfC}$ suspension. Even though a large amount of the suspension was used, an extremely thin HfC coating of approximately submicron thickness was obtained. When a HfC suspension with a concentration of approximately $0.7 \mathrm{vol} \%$ was used instead of the $10 \mathrm{wt} \%$ suspension, a HfC coating could not be formed because of the excessive amount of the solvent. The enthalpy transferred to the HfC particles decreased since most of the enthalpy of the plasma flame was used for evaporating the ethanol solvent in the HfC suspension [20]. The unmelted HfC particles only collided with the substrate and did not adhere to the substrate surface to form a coating. To increase the coating deposition rate and deposition efficiency and inhibit the oxidation of HfC during SVPS, a HfC coating was fabricated at a lower working pressure and a higher solid concentration. Figure 4(b) shows that a dense HfC coating with a uniform thickness
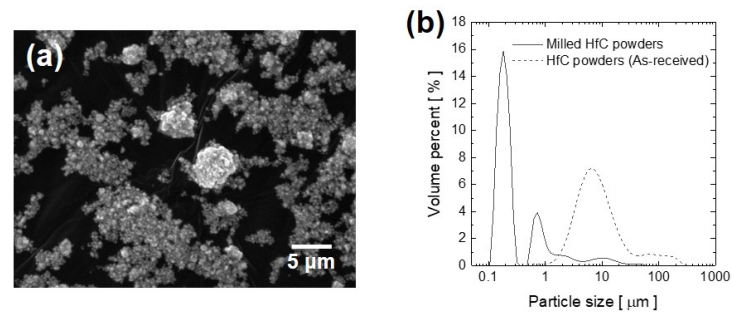

Figure 3. (a) SEM image of crushed HfC powder and (b) particle size distribution of as-received and crushed $\mathrm{HFC}$ powders.
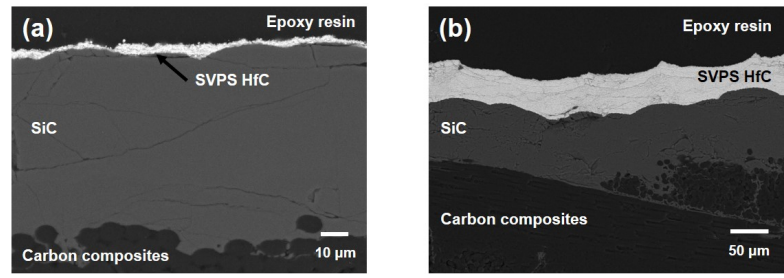

Figure 4. Cross-sectional SEM image of $\mathrm{HfC}$ coating fabricated at (a) working pressure of 100 mbar using 10 wt\% HfC suspension and (b) working pressure of 50 mbar using 20 wt\% HfC suspension. 


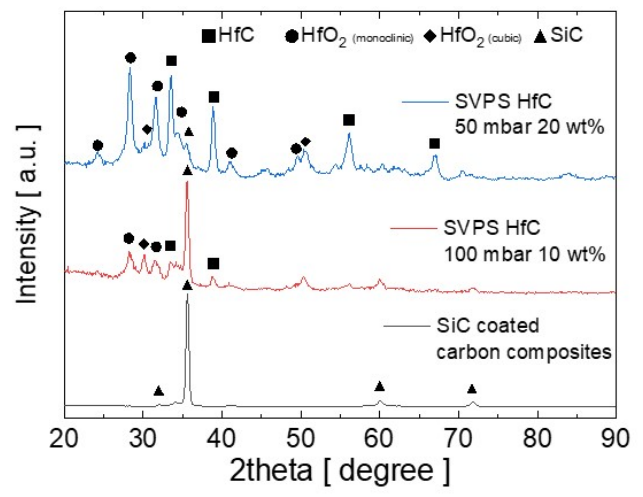

Figure 5. XRD spectra of $\mathrm{HfC}$ coatings.

of over $50 \mu \mathrm{m}$ was formed at a working pressure of 50 mbar using a $20 \mathrm{wt} \% \mathrm{HfC}$ suspension. The enthalpy of the plasma flame required for solvent evaporation decreased as the concentration of HfC particles in the suspension increased. This increased the number of molten particles during the process and resulted in a higher deposition efficiency. As working pressure decreases, the mean free path of plasma ions increases because interparticle collisions decrease. This increases the length of the plasma flame and the dwell time of the spray particles in the plasma flame. Thus, more enthalpy of the plasma flame is transferred to the spray particles, and the particles melt completely [23,24]. The fully molten particles collided with the substrate and adhered well to the substrate surface. The number of cracks in the HfC coating fabricated at a working pressure of 50 mbar was less than that in the $\mathrm{HfC}$ coatings fabricated at a higher working pressure because of the reduction in the thermal stress induced in the HfC coating during SVPS When dense thermal sprayed coatings are formed, cracks are initiated owing to the thermal stress accumulated because of the collision of hot particles and quenching. Fully molten powders are more elastic than unmelted powders. This reduces thermal stress, and thus, the number of cracks in the dense SVPS coatings decreases.

Figure 5 shows the XRD spectra of the HfC coatings fabricated via SVPS. The XRD spectrum of the HfC coating fabricated at $100 \mathrm{mbar}$ shows that a small amount of the HfC coating consisting of hafnium oxide $\left(\mathrm{HfO}_{2}\right)$ was formed on the $\mathrm{SiC}$ layer. Even at $50 \mathrm{mbar}$, a $\mathrm{HfC}$ coating containing $\mathrm{HfO}_{2}$ was formed; however, the fraction of $\mathrm{HfO}_{2}$ in the HfC coating decreased. HfC oxidized during SVPS owing to the high temperature of the plasma flame and the presence of oxygen in the ethanol solvent. The $\mathrm{H}_{2}$ in the plasma gas reacted with the oxygen inside the plasma flame. This resulted in a reduction reaction, which accelerated as the working pressure decreased.

The carbon composites and HfC coatings were subjected to laser oxidation at $2000{ }^{\circ} \mathrm{C}$ for $20 \mathrm{~s}$. Figure 6 shows the change in the weight of the specimens and the cross-sectional SEM image of the HfC coating oxidized at $2000{ }^{\circ} \mathrm{C}$. The weight of the uncoated carbon composites reduced by approximately $1.5 \%$ every $10 \mathrm{~s}$ because carbon begins to oxidize over $400{ }^{\circ} \mathrm{C}$ [25]. The weight of the HfC-coated carbon composites reduced by approximately $0.2 \%$ every $10 \mathrm{~s}$; this was seven times less than the weight reduction rate of the uncoated carbon composites. HfC started to oxidize at a low temperature (400 to $500{ }^{\circ} \mathrm{C}$ ) and formed $\mathrm{HfO}_{2}$ [26]. The difference between the weight reduction rates of the uncoated and $\mathrm{HfC}$-coated carbon composites was due to the difference in the phase of the product after oxidation. Carbon oxidizes to form carbon dioxide, which escapes in the gaseous state. However, $\mathrm{HfC}$ oxidizes to form $\mathrm{HfO}_{2}$, which exists in the solid state even at $2000{ }^{\circ} \mathrm{C}$. Thus, a solid $\mathrm{HfO}_{2}$ layer formed on the surface of the HfC coating during laser oxidation and prevented the ox- (a)
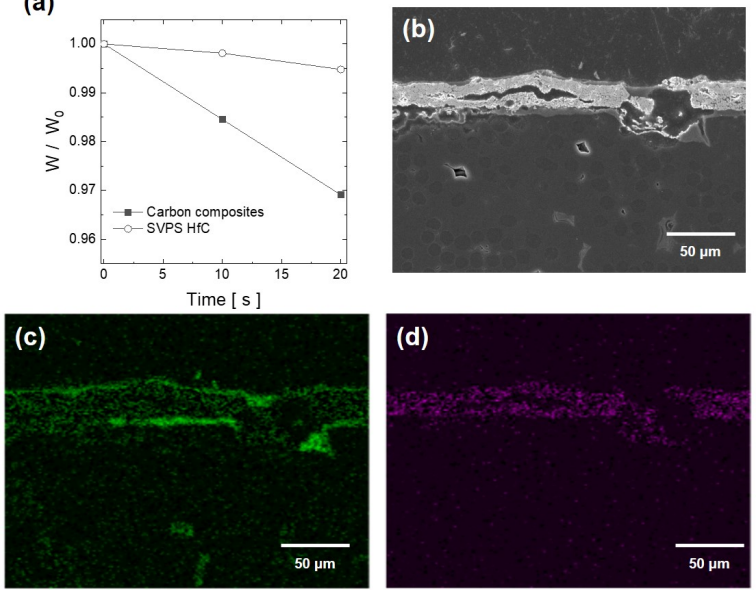

Figure 6. (a) Change in weight of uncoated and HfC-coated carbon composites after laser oxidation test at $2000^{\circ} \mathrm{C}$. (b) Cross-sectional SEM image of $\mathrm{HfC}$ coating after laser oxidation test at $2000^{\circ} \mathrm{C}$. (c) EDS map of Si. (d) EDS map of $\mathrm{Hf}$ in $\mathrm{HfC}$ coating after laser oxidation test at $2000^{\circ} \mathrm{C}$.

idation and evaporation of the underlying carbon. Figure 6(b) shows the cross section of the HfC coating after laser oxidation. The Hfcontaining surface layer remained, even though it was partially delaminated. Figures 6(c) and 6(d) show the energy dispersive X-ray spectroscopy (EDS) mapping analysis of silicon and $\mathrm{Hf}$ in the oxidized $\mathrm{HfC}$ coating. The Hf-containing layer was composed of $\mathrm{HfO}_{2}$ and hafnium silicate $\left(\mathrm{HfSiO}_{4}\right)$. The $\mathrm{HfC}$ layer oxidized to $\mathrm{HfO}_{2}$, and the underlying $\mathrm{SiC}$ layer oxidized to silicon dioxide $\left(\mathrm{SiO}_{2}\right) . \mathrm{SiO}_{2}$ melted above $1700{ }^{\circ} \mathrm{C}$, and the liquid $\mathrm{SiO}_{2}$ flowed out and reacted with $\mathrm{HfO}_{2}$ to form $\mathrm{HfSiO}_{4}$. The unreacted $\mathrm{SiO}_{2}$ boiled under the $\mathrm{HfO}_{2}$ layer and caused the delamination of the coating and weight reduction in the specimen. However, the matrix and fibers in the carbon composites were not damaged during laser oxidation. The $\mathrm{HfC}$ and $\mathrm{SiC}$ coatings acted as oxidation barrier layers to prevent the oxidation of the carbon composites. The absence of the $\mathrm{SiC}$ layer can minimize damage to carbon composites and the delamination of HfC coatings. However, the $\mathrm{SiC}$ layer is essential for protecting the carbon composites from heated and accelerated particles during plasma spraying. The $\mathrm{SiC}$ layer should be replaced with another material that does not melt or evaporate when oxidized at a high temperature. This requires further research

\section{Conclusion}

HfC coatings were deposited on carbon composites via SVPS. Submicrometer-sized HfC powders were crushed to nanometer-sized powders using high-energy ball milling and dispersed in ethanol to prepare a HfC suspension. The HfC coating decreased the weight reduction rate of the specimens by forming $\mathrm{HfO}_{2}$ and $\mathrm{HfSiO}_{4}$ in an ultra-high-temperature laser oxidation test. In addition, it acted as an oxidation barrier layer to protect the underlying carbon composites. However, the HfC coating was partially oxidized during the spraying process owing to the reaction with the oxygen present in the solvent.

\section{Acknowledgments}

This work was supported by the Korean Government (Defense Acquisition Program Administration, DAPA) through the Agency for Defense Development (ADD). 


\section{References}

[1] O. Cedillos-Barraza, D. Manara, K. Boboridis, T. Watkins, S. Grasso, D. D. Jayaseelan, R. J. M. Konings, M. J. Reece, and W. E. Lee, Sci. Rep. 6, 37962 (2016).

[2] A. Paul, D. D. Jayaseelan, S. Venugopal, E. Zapata-Solvas, J. G. P. Binner, B. Vaidhyanathan, A. Heaton, P. M. Brown, and W. E. Lee, Am. Ceram. Soc. Bull. 91, 22 (2012).

[3] A. Sayir, J. Mater. Sci. 39, 5995 (2004).

[4] A. Paul, S. Venugopal, J. G. P. Binner, B. Vaidhyanathan, A. C. J. Heaton, and P. M. Brown, J. Eur. Ceram. Soc. 33, 423 (2013).

[5] W. Tan, K. Li, H. Li, J. Zhang, C. Ni, A. Cao, and C. Ma, Vacuum 116, 124 (2015).

[6] L. Shu-Ping, L. Ke-zhi, L. He-Jun, L. Yu-Long, and Y. Qin-Lu, Mater. Sci. Eng. A 517, 61 (2009).

[7] V. K. Wunder, N. Popovska, and G. Emig, J. Phys. IV 9, 509 (1999).

[8] Y. L. Wang, X. Xiong, G. D. Li, H. B. Zhang, Z. K. Chen, W. Sun, and X. J. Zhao, Surf. Coat. Technol. 206, 2825 (2012).

[9] Y. L. Wang, X. Xiong, G. D. Li, X. J. Zhao, Z. K. Chen, W. Sun, and Z. S. Wang, Solid State Sci. 20, 86 (2013).

[10] Y. J. Wang, H. J. Li, Q. G. Fu, H. Wu, D. J. Yao, and B. B. Wei, Appl. Surf. Sci. 257, 4760 (2011).

[11] Y. L. Wang, Z. H. Li, X. Xiong, X. B. Li, Z. K. Chen, and W. Sun, Appl. Surf. Sci. 390, 903 (2016).

[12] F. Z. Mohammad, K. J. Lawson, and J. R. Nicholls, Surf. Eng. 23, 183 (2007).

[13] W. Li, J. Meng, P. Liu, H. M. Du, K. Zhang, F. C. Ma, X. K. Liu, and X. H. Chen, Vacuum 128, 230 (2016).
[14] Y. Yang, K. Z. Li, and H. J. Li, Adv. Compos. Lett. 24, 113 (2015).

[15] Y. Yang, K. Z. Li, Z. G. Zhao, and H. J. Li, Ceram. Int. 42, 4768 (2016).

[16] Y. Yang, K. Z. Li, G. X. Liu, and Z. G. Zhao, J. Mater. Sci. Technol. 33, 1195 (2017).

[17] H. I. Yoo, H. S. Kim, B. G. Hong, I. C. Sihn, K. H. Lim, B. J. Lim, and S. Y. Moon, J. Eur. Ceram. Soc. 36, 1581 (2016).

[18] Y. C. Ye, H. Zhang, Y. G. Tong, and S. X. Bai, Ceram. Int. 39, 5477 (2013).

[19] A. Vardelle et. al., J. Therm. Spray Technol. 25, 1376 (2016).

[20] F. L. Toma, A. Potthoff, L. M. Berger, and C. Leyens, J. Therm. Spray Technol. 24, 1143 (2015).

[21] P. Fauchais, M. Vardelle, S. Goutier, and A. Vardelle, J. Therm. Spray Technol. 24, 1498 (2015).

[22] G. Mauer, N. Schlegel, A. Guignard, R. Vaßen, and O. Guillon, J. Therm. Spray Technol. 24, 1187 (2015).

[23] J. L. Dorier, M. Gindrat, Ch. Hollenstein, M. Loch, A. Refke, A. Salito, and G. Barbezat, Proceedings of the 2nd ITSC, edited by C. C. Berndt, et al. (Singapore, 2001), pp. 759-764.

[24] A. Refke, D. Hawley, J. Doesburg, and R. Schmid, Proceedings of the International Thermal Spray Conference, edited by E. Lugscheider and D. von Hofe (Basel, Switzerland, May 2-4, 2005), pp. 438-443.

[25] D. W. McKee, Chem. Phys. Carbon(CRC Press, Florida, 1991) vol. 23, pp. 173-232.

[26] S. Shimada, M. Inagaki, and K. Matsui, J. Am. Ceram. Soc. 75, $2671(1992)$ 